Article

\title{
Continuous Pyrolysis Technology for Oily Sludge Treatment in the Chain-Slap Conveyors
}

\author{
Xinxin Tang, Xuesong Wei * and Songying Chen * (D) \\ Key Laboratory of High-Efficiency and Clean Mechanical Manufacture, School of Mechanical Engineering, \\ Shandong University, Jinan 250061, China \\ * Correspondence: weixuesong@sdu.edu.cn (X.W.); chensy66@sdu.edu.cn (S.C.)
}

Received: 5 June 2019; Accepted: 28 June 2019; Published: 1 July 2019

check for updates

\begin{abstract}
In the process of petroleum exploitation, the annual production of oily sludge in China's petroleum exploitation industry alone has exceeded one million tons, which causes great harm to the environment. In order to face this problem, a variety of treatment methods have been sprung out, but the most of them are polluting the local soil and groundwater eco-environment. Pyrolysis technology for sludge treatment has several advantages, which have already made it a mainstream approach attracting worldwide attention. In this work, oily sludge from Yanshan Petrochemical Company was processed at the newly developed industrial-scale reactor. The sludge transportation in the whole system was achieved by the use of chain plate conveying, which has the advantages of preventing coking, effective sealing of sludge inlet and outlet, etc. First, lab-scale experiments were carried out at temperatures between $450{ }^{\circ} \mathrm{C}$ and $600{ }^{\circ} \mathrm{C}$ to obtain the best reaction conditions in the industrial-scale equipment. It was found that the maximum pyrolysis oil yield of $17.1 \mathrm{wt} . \%$ was obtained at $500{ }^{\circ} \mathrm{C}$. The properties of oily sludge and related compositional characterization of the products (permanent gas, pyrolysis oil, and pyrolysis char) after the treatment were comprehensively analyzed. The study showed that the oily sludge in the reactor was completely converted, and resource utilization of the feedstock could be realized.
\end{abstract}

Keywords: oily sludge; continuous pyrolysis; industrial-scale reactor; product analysis

\section{Introduction}

Oily sludge is the main pollutant produced during the process of crude oil extraction, gathering, and refining, which is in the form of the emulsion system composed of water, petroleum hydrocarbons, and solid mud sand. It has the characteristics of complex composition and difficult degradation and causes serious environmental hazards [1]. If left untreated, it will not only occupy a lot of cultivated land, but will also pollute the surrounding soil, water, and air [2].

With the increasing tight supply of petroleum resources and the further improvement of environmental protection regulations, the reduction, harmlessness, and resource utilization of oily sludge has become the inevitable trend. As one kind of treat method with the advantages of thorough disposal, less secondary pollution and high recovery rate of resources, oily sludge pyrolysis treatment has attracted close attention in the field of sludge disposal [3].

Pyrolysis treatment of oily sludge refers to the process of converting high-chain organic matter into low-carbon small molecular matter under the condition of oxygen isolation. During this process, the sludge is converted into three phase substances: Solid phase (inorganic minerals and residual carbon), liquid phase (normal temperature fuel and water), and gas phase $\left(\mathrm{CH}_{4}\right.$ and $\mathrm{H}_{2}$, etc.) [4] . In addition, the pyrolysis residue of oily sludge basically met the requirements of BDAT in the United States so that it can be directly landfilled. 
A complete pyrolysis unit includes a feed system, a pyrolysis reactor, a vapor recovery system, a purification system, and matching control system. Due to the advantages of pyrolysis, relevant research and application have been rapidly developed. Several pyrolysis devices which are widely used are mainly as follows: Laval University in Canada and ULB University in Belgium developed a vacuum moving bed pyrolysis process and a two-stage moving bed pyrolysis process, respectively [5]; Kaminsky's team in Germany was the first to study a circulating fluidized bed reactor for the pyrolysis of oily sludge [6]. The team conducted several experiments on a circulating fluidized bed unit with a capacity of $1-3 \mathrm{~kg} / \mathrm{h}$. The reaction temperature was controlled at $460{ }^{\circ} \mathrm{C}-650{ }^{\circ} \mathrm{C}$, and the recovery rate of pyrolysis oil was $70 \%-84 \%$. In addition, they successfully developed and debugged $10-40 \mathrm{~kg} / \mathrm{h}$ circulating fluidized bed reactor for plastic and sludge pyrolysis. Black J W et al. [7] studied the pyrolysis of solid waste materials in a pilot plant of continuous ablation bed process under certain pyrolysis conditions, and finally obtained $54 \mathrm{wt} \%$ pyrolysis oil yield. Chen et al. [8] carried out an experimental study on sludge pyrolysis in a rotary reactor with a treatment scale of $1-2 \mathrm{~kg} \cdot \mathrm{h}^{-1}$. The reaction conditions were as follows: Argon was used as inert atmosphere, temperature was controlled at $550{ }^{\circ} \mathrm{C}$, solid material diameter was $2-4 \mathrm{~cm}$, and residence time was $45-60 \mathrm{~min}$. After the experiment, the three phase products of solid, liquid, and gas were treated and analyzed. Janetta [9] studied steam plasma torch gasification of municipal sludge that came from the Sofia sewage treatment plant. The composition of the sludge showed that the sludge contained nearly $60 \%$ of organic matter and about $40 \%$ of inorganic matter. Experimental results showed that $\mathrm{CO}$ and $\mathrm{H}_{2}$ were the main gas products, while the volume of $\mathrm{CO}_{2}$ produced was less than $4 \%$. There was no methane in the gas product, but hydrogen sulfide was produced. Ayen et al. [10] developed a "low temperature heat treatment" process in 1992. The organic matter and water in the oil position were evaporated in a closed rotary heater at a temperature of $250-450{ }^{\circ} \mathrm{C}$, and nitrogen gas was used as a carrier gas to be sent to the evaporation treatment system. This process enabled the "solid waste" to meet BDAT requirements after treatment and has been commercialized. According to Daya Shankar Pandey [11], the formation of products (gases, biochar, and bio-oil) during the fast pyrolysis of poultry litter was experimentally investigated in a laboratory-scale bubbling fluidized bed reactor. Pyrolytic gases accounted for 15-22 wt.\% of the product. Rubab Sarfraz et al. [12] found that the yields and properties of biochar depended principally on the applied temperature where pyrolysis at higher temperatures, that is, $600{ }^{\circ} \mathrm{C}$ and $700^{\circ} \mathrm{C}$ produced biochar having high ash, $\mathrm{P}$, and $\mathrm{K}$ contents. Moreover, numerous useful macro- and micronutrients, such as $\mathrm{Ca}, \mathrm{Mg}$, $\mathrm{Fe}$, and $\mathrm{Zn}$, were observed to positively correlate with the increase in temperature. Akyürek [13] carried out the pyrolysis tests performed at 10, 30, and $50{ }^{\circ} \mathrm{C} \cdot \mathrm{min}^{-1}$ heating rate from room temperature to $1000{ }^{\circ} \mathrm{C}$ under a nitrogen environment with a flow of $100 \mathrm{~cm}^{3} \cdot \mathrm{min}^{-1}$. Kinetics of decomposition were analyzed using the Flynn-Wall-Ozawa (FWO) method. Neto [14] did work involving a preliminary phase concerned with the operation of vacuum pyrolysis of scrap tires at a laboratorial scale, followed by the design of the pilot plant that operated for 10 years, at the time of the study, with a $100 \mathrm{~kg} / \mathrm{h}$ batch flow. Results show that the yield of the pyrolysis process was $41 \%$ pyrolytic oil, $38 \%$ carbon black, $12 \%$ gas, and $8.9 \%$ steel scrap.

At present, most of the researches on sludge pyrolysis technology are only in the laboratory and pilot stage. The industrialized production equipment is rarely put into operation. Apart from municipal waste, there is basically no report on the industrial application of pyrolysis treatment of oily sludge.

The purpose of this study was to evaluate the pyrolysis process of oily sludge in a continuous pyrolysis reactor with a chain plate conveyor. The structure and working process of the equipment system were introduced. The advantages of this device are as follows: The scraper in the chain plate conveying device was used to solve the coking problem. The pyrolysis process was divided into two parts, dry and cracking, which are carried out separately in two devices. The heating source of the pyrolysis device was from the combustor, while that of the drying device was the waste heat flue gas out of the pyrolysis device, realizing the heat recycling. In this work, oily sludge from Yanshan Petrochemical Company was processed at the reactor. The experimental investigations were 
under certain conditions whose information was provided by the results of several lab-scale tests. The composition and possible applications for the three phase products were analyzed and discussed.

\section{Material and Methods}

\subsection{Feedstock}

In this experiment, the oily sludge from Yanshan Petrochemical was used as the feedstock sampled in November 2018. The visual morphological characteristics of this sludge were dark brown, viscous semi-solid emulsified material with a foul odor. Moisture and oil content were determined using CJ/T 221-2005. Homogeneous sludge samples were steamed in a constant weight evaporating dish by water bath and baked in an oven at $103-105{ }^{\circ} \mathrm{C}$ to a constant weight. The mixed solvent of dichloromethane solvent and methanol (97:3, by volume) was used as an extraction reagent. Dried sample was heated and extracted by a Soxhlet extractor for 48 hours to separate the oil phase and the solid insoluble matter, while the solvent contained in the oil phase was removed using a rotary evaporator to obtain the oil phase component. Volatile Matter and Fixed Carbon were determined according to the GB/T212-2008. The ash content was determined following the GB/T 508-1985.The filter paper and the dried sludge were placed together in a weighed magnetic enthalp. After heated and carbonized in an electric furnace, it was then placed in a muffle furnace $\left(600^{\circ} \mathrm{C}\right)$ for $50 \mathrm{~min}$. After that, the residue was taken out and placed in a desiccator for cooling. The $\mathrm{CHNO}$ analysis was carried out using the GB/T 19143-2003.

\subsection{Lab Scale Procedure}

\subsubsection{Fixed Bed Reactor}

In order to obtain the best reaction conditions in the industrial-scale continuous pyrolysis reactor, a fixed-bed pyrolysis reactor was set up independently to carry out the pyrolysis experiments of the oily sludge for investigating the effect of reaction temperature on liquid phase yield. Given the consistency of lab-scale and industry-scale tests, the raw materials used in the fixed bed reactor are as same as what are in the continuous reactor. Experiments were carried out at temperature of $450{ }^{\circ} \mathrm{C}, 500{ }^{\circ} \mathrm{C}$, $550^{\circ} \mathrm{C}$, and $600^{\circ} \mathrm{C}$, at constant residence time of $50 \mathrm{~min}$. About $20 \mathrm{~g}$ of sludge was treated during the process of each experiment. Nitrogen was used as carrier gas at $100 \mathrm{~mL} / \mathrm{min}$. The pyrolysis chars and liquids were collected and weighed separately, while the mass of the gas product was obtained by difference. The experimental heating tube was made of quartz with an outer diameter of $48 \mathrm{~mm}$, an inner diameter of $40 \mathrm{~mm}$, and a length of $730 \mathrm{~mm}$. DCS control was used to monitor the process and record the relevant data. The schematic diagram of the device is shown in the Figure 1. 


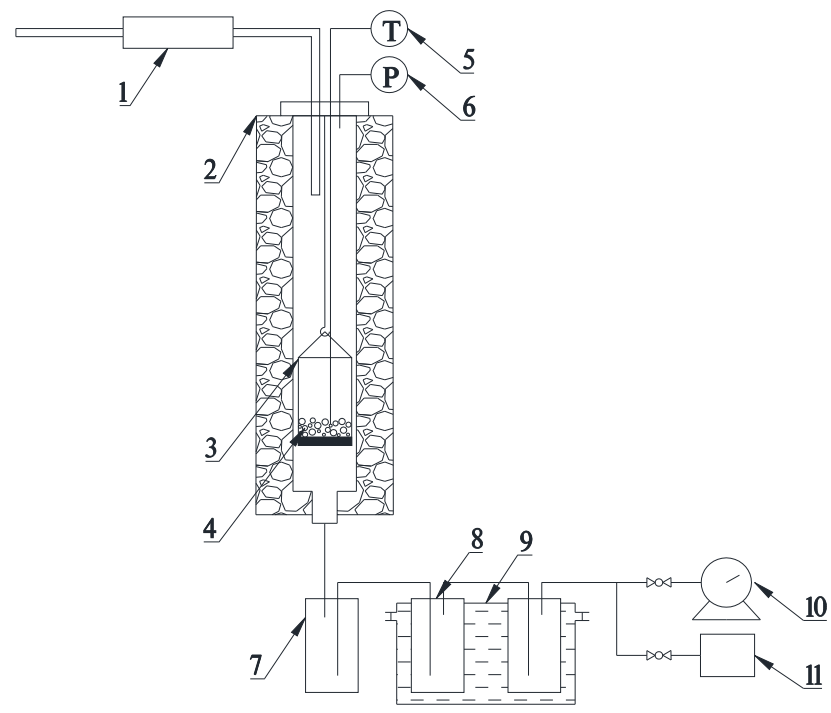

Figure 1. The schematic diagram of the fixed-bed pyrolysis reactor. Notes: 1. Flowmeter; 2. Electric furnace; 3. Quartz sample bracket; 4. Sample; 5. Thermocouple; 6. Pressure gauge; 7. Air condenser; 8. Water/glycol condenser; 9. Circulating water/glycol; 10. Gas flowmeter; 11. Gas collection.

\subsubsection{Experimental Procedure}

The sludge sample was placed in the quartz basket and suspended in the fixed bed constant temperature zone. Upper end of the reactor was connected to the carrier gas line, while the lower end was connected to the inlet of the condensing device. Liquid products produced during the pyrolysis process were condensed and collected, while the gas phase product was directly vented. Taking into account the relevant characteristics of oily sludge, first stage of the condensing system was air cooled, while at the second and third stage, the condensed product was collected at $-15^{\circ} \mathrm{C}$.

\subsection{Industrial-Scale Procedure}

\subsubsection{Continuous Pyrolysis Reactor}

Industrial-scale continuous pyrolysis reactor with separate drying and pyrolysis process was developed, which consists of seven systems: Homogeneous treatment and feed system, combustor, sludge dryer, pyrolysis reactor, condensation and separation system, flue gas treatment system, and process detection and control system. The process of the whole plant was followed: Feedstock was transported to the entrance of the system through a screw pump, then a large proportion of dry sludge was mixed with the initial sludge through mixing in the back mixing bin to reduce the water content (up to $45-55 \%$ ). After this pretreatment step, the sludge (the particle size of $10 \mathrm{~mm}$ or less) was sent to a dryer for deep drying. In the dryer, water and some light hydrocarbon vapors produced during drying processes are condensed and recovered after cyclone dedusting. The moisture content of the dried sludge can be decreased to less than $25 \%$.

Afterward, it was transported and heated under oxygen-insulated conditions in the pyrolysis reactor. During the process, organic matters were converted into pyrolysis gas and oil vapors, which were sent back to the combustor for energy supply. Residue was discharged from the outlet, while the flue gas out of the pyrolysis reactor continued to heat the dryer, and was eventually discharged after being treated and pressurized until meeting the emission standards. The appearance and flow sheet of the device is shown in Figures 2 and 3. 


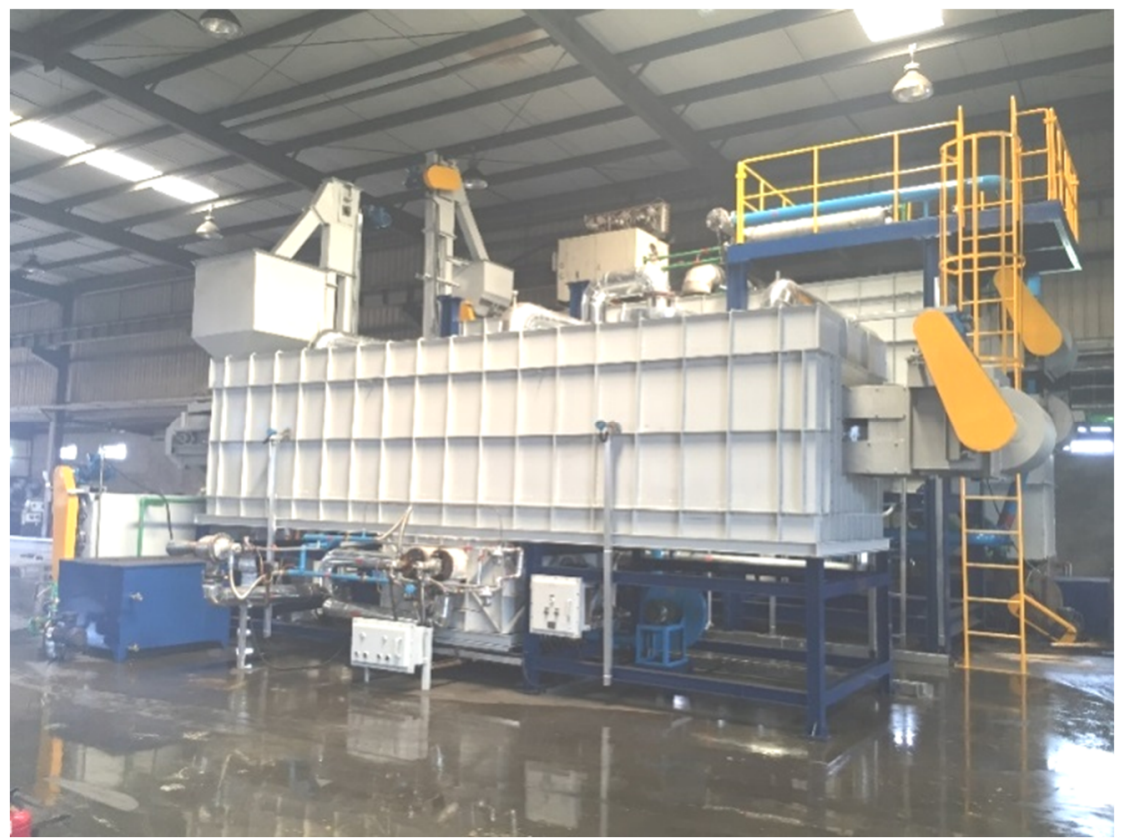

Figure 2. The appearance of the industrial-scale continuous pyrolysis reactor.

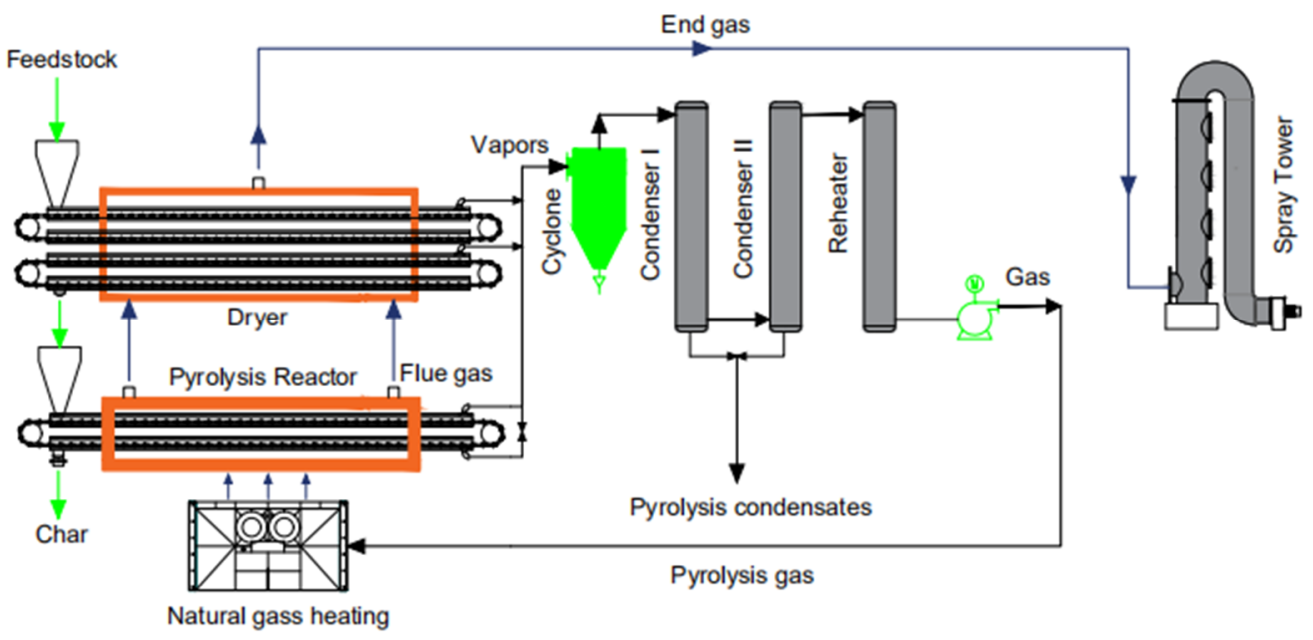

Figure 3. Flow sheet of the whole system.

\subsubsection{Industrial-Scale Procedure}

In the equipment, the oxygen-insulated environment was realized by the suction of the fan. Several thermocouples were placed in the internal reaction zone of the reactor to monitor the reaction temperature. Through the control of gas burner (cycle start-stop control), working temperature can be adjusted to achieve to what was needed for the experiment. Besides, the residence time in the reactor was controlled by adjusting the conveying speed of the chain conveyor.

Experiments were carried out at temperature of $500{ }^{\circ} \mathrm{C}$, at constant residence time of $50 \mathrm{~min}$. The mass flow rate was set at $416.67 \mathrm{~kg} \cdot \mathrm{h}^{-1}$ in the all runs. About $10,000 \mathrm{~kg}$ of oily sludge was successfully treated for a total of $24 \mathrm{~h}$ of operations. Proximate analysis, as well as ultimate analysis, was conducted according to the respective standards. The condensate is collected at a temperature of $10^{\circ} \mathrm{C}$. GC-MS was performed to identify the most abundant species of the liquid pyrolysis products. The analyses were conducted using Varian-300, in which the column is a Splitless HP-5ms $30 \mathrm{~m} \times 0.25 \mathrm{~mm} \times 0.25 \mu \mathrm{m}$. and Helium was used as carrier gas. The oven temperature profile was as follows: Held for $6 \mathrm{~min}$ at $40^{\circ} \mathrm{C}$, followed by a ramp at $4{ }^{\circ} \mathrm{C} / \mathrm{min}$ to $280^{\circ} \mathrm{C}$. The temperature was held for $10 \mathrm{~min}$. In this experiment, it 
was relatively hard to collect the permanent gas as it was directly fed into the combustion chamber for energy supply. thus, detailed component analysis was not done in this paper. Composition of heavy metal elements in the pyrolysis char was carried out in the ICP-AES analyzer using HJ 781—2016.

\section{Results}

\subsection{Lab-Scale Experimental Results}

The product yield was shown in Table 1. According to the above analysis results, the working conditions of the reactor in the whole system were as follows: Pyrolysis temperature: $500{ }^{\circ} \mathrm{C}$; residence time: $50 \mathrm{~min}$.

Table 1. Products yields of sludge as a function of temperature.

\begin{tabular}{ccccc}
\hline Reaction Temperature & $\mathbf{4 5 0}{ }^{\circ} \mathbf{C}$ & $\mathbf{5 0 0}{ }^{\circ} \mathbf{C}$ & $\mathbf{5 5 0}{ }^{\circ} \mathbf{C}$ & $\mathbf{6 0 0}{ }^{\circ} \mathbf{C}$ \\
\hline Oil Phase (\%) & 16.7 & 17.1 & 15.9 & 14.6 \\
Water Phase (\%) & 61.7 & 61.9 & 62.8 & 64.4 \\
Permanent Gas (\%) & 4.2 & 5.2 & 9.1 & 8.5 \\
Char (\%) & 17.4 & 17.1 & 15.8 & 15.7 \\
\hline
\end{tabular}

\subsection{Feedstock}

The ultimate and proximate analyses, as well as the heating values, are reported in Table 2.

This sludge, the main feature of which is high water content, is the flocculated sludge after sewage treatment in flotation. Ultimate analysis results showed that this kind of oily sludge has high nitrogen and sulfur contents. Usually, Nitrogen comes from protein in sludge and nitrogen compounds in crude oil, such as pyridine and indole. Sulfur mainly comes from a part of residues adsorbed in oily sludge during petroleum storage and refining, and exists in the form of sulfur oxides, hydrogen sulfide, and organic sulfur (such as mercaptan, thioether, dimethyl sulfur, etc.). It should be noted that sulfur oxides and hydrogen sulfide will seriously corrode the equipment during the sludge treatment process. Thus, it is necessary to investigate the distribution of total sulfur migration in the large-scale industrial process [15]. Proximate analysis results showed that this sludge has High Volatile Matter and Fixed Carbon contents, which is completely different from the results of sewage sludge conducted by other scholars [16]. The main components of volatiles are $\mathrm{CO}, \mathrm{CO}_{2}, \mathrm{H}_{2}, \mathrm{CH}_{4}, \mathrm{~N}_{2}$, and some gaseous hydrocarbons. Higher volatile matter content is beneficial to the production of bio-oil and pyrolysis gas during pyrolysis [17]. Higher Volatile Matter and Fixed Carbon contents can contribute to higher heating values.

Table 2. Ultimate and proximate analyses of oily sludge (d.b., dry basis; a.r., as received).

\begin{tabular}{ccccc}
\hline \multicolumn{5}{c}{ Ultimate Analysis wt. $\%($ d.b.) } \\
\hline $\mathbf{C}$ & $\mathbf{H}$ & $\mathbf{O}$ & $\mathbf{N}$ & $\mathbf{S}$ \\
\hline 54.86 & 5.80 & 10.18 & 2.13 & 1.5 \\
\hline \multicolumn{5}{c}{ Proximate analysis wt.\% (a.r.) } \\
& Heating value (kcal/kg) (a.r.) \\
\hline Moisture & Ash & Volatile Matter & Fixed Carbon & LHV \\
\hline 62.67 & 8.59 & 21.51 & 7.23 & 2220 \\
\hline
\end{tabular}

Sludge oil phase extracted by Soxhlet extraction was analyzed by GC-MS. The results are shown in Figure 4. By analyzing this chromatogram, it was found that there are about 30 kinds of hydrocarbons with different numbers of 7-40 carbon atoms in the sample oil phase, of which gasoline (C7-C9) accounts for $23.19 \%$, kerosene (C10-C15) accounts for 53.65\%, diesel oil (C16-C18) accounted for $6.46 \%$, and heavy oil (C19 or above) accounted for $16.72 \%$. 


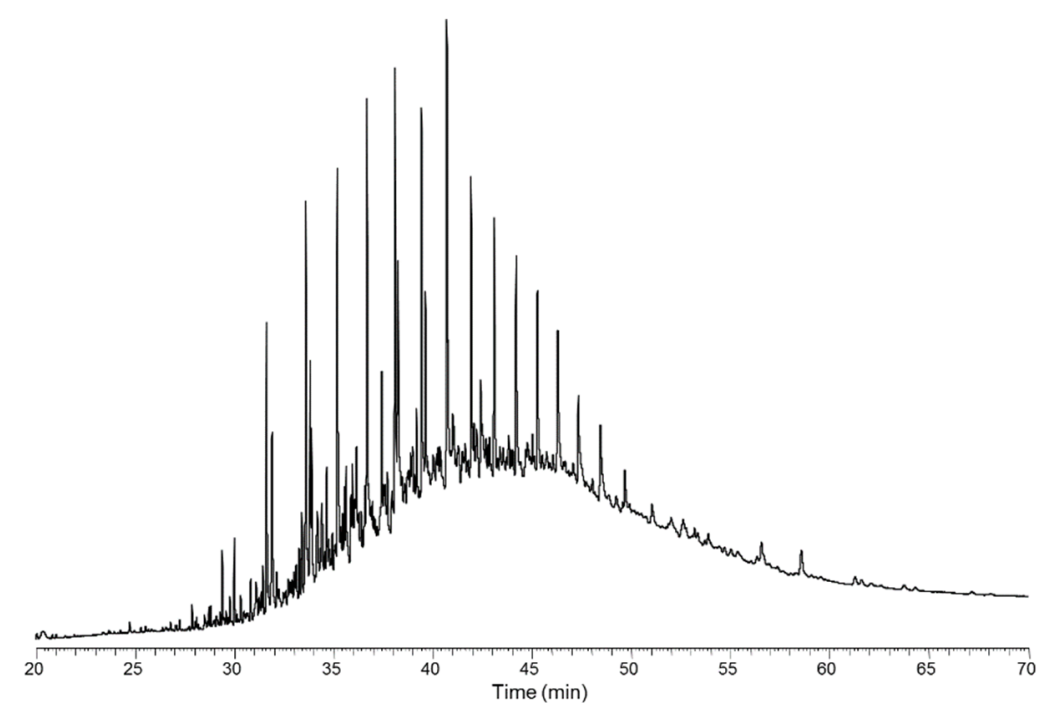

Figure 4. Gas chromatogram of oil phase components in the oily sludge.

\subsection{Pyrolysis Oil}

Oil-water separation of pyrolysis liquids was conducted, then the oil phase was sampled with a micro-syringe and additional ultimate analysis was performed, the results of which are reported in Table 3.

Table 3. Ultimate and proximate analyses of pyrolysis oil (d.b., dry basis; a.r., as received).

\begin{tabular}{ccccc}
\hline \multicolumn{5}{c}{ Ultimate analysis wt.\%(d.b.) } \\
\hline C & $\mathbf{H}$ & $\mathbf{O}$ & $\mathbf{N}$ & $\mathbf{S}$ \\
\hline 85.5 & 11.58 & 1.09 & 0.85 & 0.98 \\
\hline \multicolumn{7}{c}{ Components Analysis } & & Heating value (kcal/kg) (a.r.) \\
\hline C7-C9 & C10-C15 & C16-C18 & C19 or above & LHV \\
\hline 12.2 & 60.1 & 8.2 & 19.4 & 9682 \\
\hline
\end{tabular}

According to the ultimate analysis, the $\mathrm{C}$ content in the char was greatly increased, and the $\mathrm{O}$ content was reduced, which was due to the deoxidation reaction. This led to a decrease in the O/C ratio, thereby increasing the energy density.

Combined with the qualitative analysis of gas chromatography, a total of 87 peaks below C23 were confirmed. Most of the signal peaks in the chromatogram correspond to linear normal paraffins with a carbon number of 6-44, which was the major components of the paraffin product. Besides, the pyrolysis oil can be further refined to develop a range of petroleum products [18].

\subsection{Pyrolysis Char}

The residue from pyrolysis is shown in Figure 5. It can be seen that it is the black powder with significant carbon content and agglomeration. 

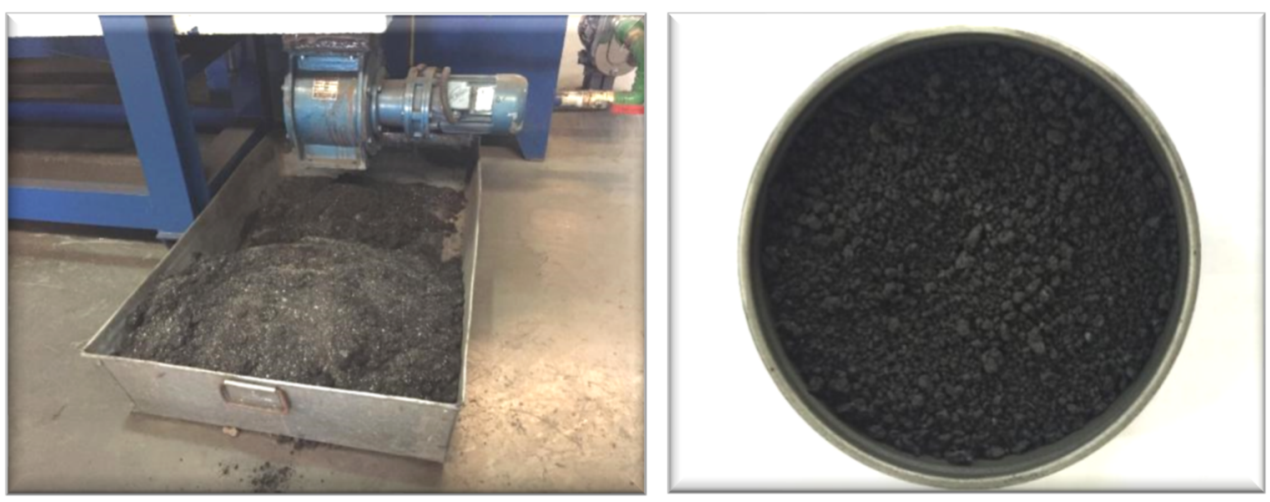

Figure 5. The appearance of the pyrolysis char.

Pyrolysis char was analyzed for ultimate, proximate analysis and heating value, the results of which are shown in Table 4. It was easily seen that the ash content of the residue was high, close to $50 \%$, indicating that the ash was almost completely recovered in carbon. This is of great benefit to the utilization of bio-oil (e.g. syngas from bio-oil gasification), because syngas from bio-oil is much cleaner and easier to purify than that directly from biomass gasification. Besides, the fixed carbon content is high, leading to its higher heating value. Thus, it can be burned for energy supply in industrial applications. However, due to its high nitrogen and sulfur content, it is necessary to post-treat the exhaust gas or migrate these elements in advance.

The ultimate analysis results revealed that the $\mathrm{H} / \mathrm{C}$ and $\mathrm{O} / \mathrm{C}$ ratios in char decreased. These two ratios are related to the aromaticity and hydrophilicity of the substance, the former being positively correlated and the latter being inversely related. Therefore, the aromaticity of the char was increased and the hydrophilicity was weakened, which indicated that the biomass carbon prepared by pyrolysis was more stable. In addition, its low $\mathrm{O} / \mathrm{C}$ ratio may result in higher efficiency during gasification. The decrease in the content of $\mathrm{N}$ indicates that it is easily converted to volatiles.

After exploring the oil content of pyrolytic char, it was found that the oil content of pyrolytic carbon was less than $0.3 \%$, indicating that it was basically out of the category of hazardous waste. The pyrolysis char which has not been subjected to secondary treatment is not suitable for the application of activated carbon, but its physical properties can be utilized as an adsorbent. The adsorption performance of the residue is so poor, but the sludge-based adsorbent with a large specific surface area and a relatively developed micro-porous pore could be prepared after its activation modification [19]. Another potential application is to pour the char into the soil in order to improve $\mathrm{C} / \mathrm{N}$ ratio after being treated to meets the emission standard. The optimum $\mathrm{C} / \mathrm{N}$ ratio in soil is 30 to 1 , which is conducive to microbial reproduction and plant growth.

Table 4. Ultimate and proximate analyses of pyrolysis char (d.b., dry basis; a.r., as received).

\begin{tabular}{|c|c|c|c|c|}
\hline \multicolumn{5}{|c|}{ Ultimate analysis wt.\%(d.b.) } \\
\hline $\mathrm{C}$ & $\mathrm{H}$ & $\mathrm{O}$ & $\mathrm{N}$ & $\mathrm{S}$ \\
\hline 43.65 & 1.46 & 0.49 & 1.27 & 2.58 \\
\hline \multicolumn{4}{|c|}{ Proximate analysis wt.\% (a.r.) } & Heating value (kcal $/ \mathrm{kg})$ (a.r.) \\
\hline Moisture & Ash & Volatile Matter & Fixed Carbon & LHV \\
\hline 2.16 & 52.71 & 21.51 & 36.98 & 3690 \\
\hline
\end{tabular}

The composition of heavy metal elements in the pyrolysis char, carried out in the ICP-AES analyzer, is reported in the Table 5 . Unfortunately, the content of some metals exceeded the agricultural sludge standards in GB15618-208, such as As, Pb, and Ni, while the Zn element was seriously exceeded. Therefore, relevant post-treatment is required to reduce the heavy metal content in the pyrolysis char. 
Table 5. The composition of heavy metal elements in the pyrolysis char.

\begin{tabular}{cccccccc}
\hline & As & Cd & Pb & Ni & Cr & Zn & Cu \\
\hline Content $(\mathrm{mg} / \mathrm{kg})$ & 160.50 & 3.22 & 623.9 & 764.7 & 233.3 & 10867.7 & 266.70 \\
\hline \multicolumn{7}{c}{ Maximum } & permissible content $(\mathrm{mg} / \mathrm{kg})$ \\
\hline $\begin{array}{c}\text { In acidic soils } \\
\quad \mathrm{PH}<6.5)\end{array}$ & 75 & 5 & 300 & 100 & 600 & 500 & 250 \\
$\begin{array}{c}\text { In alkaline soils } \\
(\mathrm{PH}>6.5)\end{array}$ & 75 & 20 & 1000 & 200 & 1000 & 1000 & 500 \\
\hline
\end{tabular}

\section{Conclusions}

In this paper, combined with the principle of continuous feeding and the mechanism of pyrolysis, a newly industrial-scale developed pyrolysis reactor for chain plate transportation was proposed, in which oily sludge from Yanshan Petrochemical was treated. In order to obtain the optimum reaction temperature, the feedstock was sampled and placed in a small test pyrolysis reactor for pyrolysis experiments. The optimal reaction conditions after multiple orthogonal experiments were: Pyrolysis temperature $500^{\circ} \mathrm{C}$, reaction time $50 \mathrm{~min}$. In accordance to the system scheme parameters, the processing capacity of $10 \mathrm{t} \cdot \mathrm{d}^{-1}$ was tested. The experiment was carried out at $500{ }^{\circ} \mathrm{C}$ and the constant residence time was adjusted for 50 minutes. Sampling of products was used for subsequent analysis. It was concluded that this continuous pyrolysis reaction device can effectively treat oily sludge. In addition, pyrolysis oil can be used to prepare paraffin products or further refinement. The pyrolysis gas can be directly used as the fuel gas of the combustor. As for the solid residue, it can be treated as an adsorbent or be put into the soil to improve the carbon-to-nitrogen ratio.

Author Contributions: Conceptualization, X.T.; Methodology, X.T. and X.W.; Software, X.T.; Validation, X.W.; Formal Analysis, X.T.; Investigation, X.T. and X.W.; Resources, S.C.; Data Curation, X.W.; Writing-Original Draft Preparation, X.T.; Writing-Review and Editing, X.T. and X.W.; Visualization, X.T. and X.W.; Supervision, S.C.; Project Administration, S.C.; Funding Acquisition, X.W.

Funding: This research was funded by [Key research and development program of Shandong Province (2016GGX104018)].

Conflicts of Interest: The authors declare there is no conflicts of interest regarding the publication of this paper.

\section{References}

1. Yu, Q. Fundamental Study on Pyrolysis Characteristics of Oil Sludge; Shenyang Institute of Aeronautical Engineering: Shenyang, China, 2008.

2. Chen, M.; Liu, Z.; Wang, X.; Xu, Z. New Technology and Development Direction of Harmless and Resource-based Treatment of Oily Sludge. Pet. Nat. Gas Chem. Ind. 2011, 40, 313-317.

3. Pramf, P.; Vissanu, M.; Chatvalee, K.; Pramoch, R.; Thirasak, R.; Boonyarach, K. Pyrolysis of APl separator sludge. J. Anal. Appl. Pyrolysis 2003, 68-69, 547-560.

4. Chen, Z.; Wei, L. Research of Oily Sludge Treatment Technology and Technological Application; The Science Publishing Company: Beijing, China, 2012.

5. Cypres, R.; Bettens, B. Production of benzoles and active car-bon from waste rubber and plastic materials by means of py-rolysis with simultaneous post-cracking. In Pyrolysis and Gasification C; Elsevier Science Publ. Co. Inc.: London, UK, 1989; pp. 209-216.

6. Karminsky, W.; Sinn, H. Pyrolysis of Plastic Waste and Scrap Tires Using a Fluidized Bed Process; American Chemical Society: Washington, DC, USA, 1980; pp. 68-77.

7. Black, J.W.; Brown, D.B. CAR Technology; Castle Capital Inc.: Clarence, NY, USA, 1991; Volume 55, pp. $203-210$.

8. Chen, C.; Li, S.; Yue, C.; Kruttschnitt, T.; Pruckner, E.; Yao, Q. Rotary Continuous Pyrolysis of Oily Sludge-Mass-Energy Balance and Product Analysis. J. Chem. Eng. 2006, 03, 650-657.

9. Janetta, R. Plasma Waste Management chemical gasification of sewage sludge. Waste Manag. Res. 2003, 21,3841 .

10. Ayen, R.; Swansrom, C.P. Low temperature thermal treatment of petroleum refinery waste sludges. Environ. Process 1992, 11, 127-132. [CrossRef] 
11. Pandey, D.S.; Katsaros, G.; Lindfors, C.; Leahy, J.J.; Tassou, S.A. Fast Pyrolysis of Poultry Litter in a Bubbling Fluidised Bed Reactor: Energy and Nutrient Recovery. Sustainability 2019, 11, 2533. [CrossRef]

12. Sarfraz, R.; Li, S.; Yang, W.; Zhou, B.; Xing, S. Assessment of Physicochemical and Nutritional Characteristics of Waste Mushroom Substrate Biochar under Various Pyrolysis Temperatures and Times. Sustainability 2019, 11, 277. [CrossRef]

13. Akyürek, Z. Sustainable Valorization of Animal Manure and Recycled Polyester: Co-pyrolysis Synergy. Sustainability 2019, 11, 2280. [CrossRef]

14. Oliveira Neto, G.C.; Chaves, L.E.C.; Pinto, L.F.R.; Santana, J.C.C.; Amorim, M.P.C.; Rodrigues, M.J.F. Economic, Environmental and Social Benefits of Adoption of Pyrolysis Process of Tires: A Feasible and Ecofriendly Mode to Reduce the Impacts of Scrap Tires in Brazil. Sustainability 2019, 11, 2076. [CrossRef]

15. Zhang, M. Determination of total sulfur in oily sludge and migration of sulfur during pyrolysis. In Proceedings of the 2014 Annual Meeting of the Chinese Society of Environmental Sciences, Chengdu, China, 22-23 October 2014; Volume 3.

16. Liu, D.; Li, Y.; Wang, M.; Wang, L. Characteristic of biomass carbon from corn straw pyrolysis at low temperature. Power Grid Clean Energy 2017, 33, 105-109.

17. Tomasi Morgano, M.; Leibold, H.; Richter, F.; Dieter, S.; Helmut, S. Screw pyrolysis technology for sewage sludge treatment. Waste Manag. 2018, 73, 487-495. [CrossRef] [PubMed]

18. Tang, C.; Guan, J.; Zhang, M.; Ma, C. Development and Adsorption Characteristics of Adsorbents for Oily Sludge. Pet. Refin. Chem. Ind. 2016, 47, 22-26.

19. Tang, H. Experimental Study on Thermal Treatment of Oily Sludge; Zhejiang University: Hangzhou, China, 2008.

(C) 2019 by the authors. Licensee MDPI, Basel, Switzerland. This article is an open access article distributed under the terms and conditions of the Creative Commons Attribution (CC BY) license (http://creativecommons.org/licenses/by/4.0/). 